\title{
Comparison of Biofilm Producing and Non-producing Escherichia coli Isolated from Urine Samples of Patients Visiting a Tertiary Care Hospital of Morang, Nepal
}

\author{
Manita Tumbahangphe ${ }^{1}$, Bijay Kumar Shrestha ${ }^{1}$, Jenish Shakya ${ }^{1}$, Hemanta Khanal ${ }^{1 *}$ \\ ${ }^{1}$ Department of Microbiology, Central Campus of Technology, Tribhuvan University, Hattisar Dharan, Nepal
}

*Corresponding author: Hemanta Khanal, Department of Microbiology, Central Campus of Technology, Dharan, Nepal; E-mail: khanal.hemanta@gmail.com

ABSTRACT

Objectives: The main objective of this study was to determine the prevalence of Escherichia coli among urinary tract infection (UTI) suspected patients visiting tertiary care hospital and to assess the biofilm producing ability of $E$. coli isolates.

Methods: A prospective cross-sectionalstudy was carried out in Biratnagar Metropolitan city, Eastern Nepal from December 2018 to May 2019. During the study 400 urine samples were collected from UTI suspected patients visiting a tertiary care hospital ofBiratnagar. Urine samples were cultured by using semi-quantitative culture technique and identified. Antibiotic susceptibility testing was done by Kirby-Bauer Disk Diffusion method according to CLSI (2011) guidelines.Biofilm assays were performed by microtitre plate method.

Results: This study reported $15 \%$ prevalence of E. coli out of 400 urine samples. $100 \%$ of E. coli isolates showed resistance to both Ampicillin and Amoxicillin while 100\% were sensitive to Chloramphenicol. 70\% (42/60) isolates wereMulti Drug Resistance (MDR)E. coli. The maximum isolates $(86.66 \%)$ were found to be biofilm producers by microtitre plate method. Resistance to other antibiotics such as Nalidixic acid (71.11\% vs $46.66 \%)$, Norfloxacin (53.33\% vs $46.66 \%)$, Cotrimoxazole (42.22\% vs $26.66 \%$ ) was comparatively higher among biofilm producers than non-biofilm producers. There was a significance of association between biofilm and MDR $(\mathrm{p}<0.05)$.

Conclusion: There is relation between the ability of biofilm formation and drug resistance in the bacterium resulting to the failure of antibacterial drugs.

Key words: E. coli, Biofilm producer, Multidrug resistance (MDR), UTI

\section{INTRODUCTION}

Escherichia coli is Gram negative, facultative anaerobic and coliform bacterium which is common colonizer of lower intestine of warm-blooded animals (Tenaillon et al. 2012). Among all the members of Enterobacteriaceae family, E. coli is the most common pathogen (80-85\%) involved in urinary tract infection (UTI) (Nicolle 2008; Bhatta et al. 2012). In case of UTI, fecal bacteria colonize urethra and spread up the urinary tract and finally to the bladder while sometimes to the kidneys causing pyelonephritis or the prostrate in males (Nicolle 2008).

During the lifetime approximately $10 \%$ of the humans acquire UTI at some time (Karki et al. 2004). The incidence of UTI is age and sex dependent example

Date of Submission: October 22, 2019

Published Online: December, 2019 women are more prone to UTI than men (Nicolle 2008). Females falling within the age group 21-30 years experiences UTI more frequently (Baral et al. 2012).

Biofilm formation is a phenomenon which is produced by microorganisms to survive in harsh environment or for establishing bacterial infection in humans (Neupane et al. 2016). This protects bacteria from antibiotics and host defenses which as a result makes the treatment of infection more difficult (Anderson et al. 2003). The interaction between the bacterial cells within a biofilm can lead to the exchange of plasmid, drug resistance marker genes and hence enhances antimicrobial resistance (Watnick et al. 2000; Kostakioti et al. 2013). Thus, biofilm mode of living is advantageous for

Date of Acceptance: December 3, 2019

DOI: https:/ / doi.org/10.3126/tujm.v6i0.26588 
uropathogens to withstand stress and antibiotic drugs in urinary tract environment (Pramodhini et al. 2012).

According to the centers for disease control and prevention, multidrug resistant (MDR) is defined as non-susceptibility to at least one agent in three or more antimicrobial categories (Magiorakos et al. 2011). The emergence of multidrug resistance E. coli in urinary tract infection has become a global concern (Mashwal et al. 2017). Study has reported E. coli being resistant against trimethoprim-sulfamethoxazole, fluoroquinolones and other antibiotics including ciprofloxacin (Karlowsky et al. 2006). The diagnosis of UTI is usually based on a quantitative urine culture yielding greater than $10^{5}$ colony forming units per $\mathrm{mL}$ (Kass et al. 1957). However, several studies suggest that more than one third of symptomatic women show CFU counts below this level (low-coliform-count infection) and that a bacterial count of $100 \mathrm{CFU}$ per $\mathrm{mL}$ of urine has a high positive predictive value for cystitis in symptomatic women (Komaroff et al. 1986; Kunin et al. 1993).The main aim of this study was to determine the prevalence of $E$. coli among UTI suspected patients visiting tertiary hospital and to assess the biofilm producing ability of E. coli isolates.

\section{MATERIALS AND METHODS}

Study site: This research was performed from December 2018 to May 2019 after receiving ethical approval from Nepal Health Research Council (NHRC), Kathmandu. During the study 400 urine samples were analyzed. All the works related to research were performed in microbiology laboratory of tertiary care hospital and of Central Campus of Technology, Dharan. The urine samples were taken from urinary tract infection suspected patients visiting a tertiary hospital of Biratnagar.

Sample collection: The midstream urine samples were collected from UTI suspected patients in sterilized screw-cap propylene bottles following standard guidelines (Isenberg 2004). The samples were then processed in microbiology laboratory as soon as after the collection. The containers were labeled with patient's name, ID number, specimen type and date of collection. In case of any delay in processing for more than 2 hours, samples were refrigerated at $4^{\circ} \mathrm{C}$.

Isolation and identification: Urine specimens were cultured by using semi-quantitative culture technique as described by Kass (1962). A loopful of well-mixed sample was inoculated using standard calibrated loop onto Cystine-Lactose-Electrolyte-Deficient Agar (CLED) (HiMedia, India) and incubated aerobically at $37^{\circ} \mathrm{C}$ for 24 hours. After overnight incubation, colony counts yielding bacterial growth of $\geq 10^{5}$ were taken as being significant for UTI. For identification of isolates, at first colony characteristics of isolated bacteria were observed on agar plates and Gram staining was done. Gram negative isolates were then further identified by performing different biochemical tests including catalase, oxidase, indole utilization test, citrate test, methyl red, VP test, carbohydrate fermentation test and triple sugar iron utilization test. Isolates other than $E$. coliwere not considered for this study.

Microtitre plate method for detection of biofilm: This method was performed as described by Borucki et al. (2003). Each culture was individually grown overnight in $10 \mathrm{~mL}$ of Trypticase Soy Broth (TSB) (HiMedia, India) at $37^{\circ} \mathrm{C}$ for 24 hours and diluted to $1: 40$ in TSB containing $0.25 \%$ glucose. Then $200 \mu$ l of diluted culture was inoculated in a sterile microtitre well. The plates were incubated at $37^{\circ} \mathrm{C}$ for 24 hours for biofilm production. After incubation, content of each well was removed by gentle tapping. The wells were washed with $0.2 \mathrm{~mL}$ of phosphate buffer saline (PBS with $\mathrm{pH}$ 7.4) for four times and finally stained with $0.1 \%$ crystal violet solution for 30 minutes. After rinsing thrice with the sterile distilled water and subsequent drying, the stain taken up by the adherent biofilm was extracted by using $95 \%$ ethanol at $4^{\circ} \mathrm{C}$. The content of each well was transferred to another microtitre well and the absorbance was measured at $595 \mathrm{~nm}$ by ELISA plate reader(Loncare LR-620 microplate reader, Medical Technology Co., Ltd.).The experiment was performed in triplicate.Interpretation was made on OD by subtracting OD of control wells from OD of test wells. The optical density $\left(\mathrm{OD}_{\mathrm{s}}\right)$ of each strain was obtained by the arithmetic mean of the absorbance of three wells and this value was compared with the mean absorbance of negative controls $\left(\mathrm{OD}_{\mathrm{nc}}\right)$. The following classification was used for the determination of biofilm formation: no biofilm production $\left(\mathrm{OD}_{\mathrm{s}} \leq \mathrm{OD}_{\mathrm{nc}}\right)$, weak biofilm production $\left(\mathrm{OD}_{\mathrm{nc}}<\mathrm{OD}_{\mathrm{s}} \leq 2 . \mathrm{OD}_{\mathrm{nc}}\right)$, moderate biofilm production $\left(2 . \mathrm{OD}_{\mathrm{nc}}<\mathrm{OD}_{\mathrm{s}} \leq 4 . \mathrm{OD}_{\mathrm{nc}}\right)$ and strong biofilm production $\left(4 . \mathrm{OD}_{\mathrm{nc}}<\mathrm{OD}_{\mathrm{s}}\right)$ (Stepanovic et al. 2007).

Antibiotic susceptibility test (AST): Antibiotic susceptibility of E. coli was evaluated against antibiotics ampicillin, chloramphenicol, sulfonamides, tetracycline, 
ciprofloxacin, trimethoprim-sulfamethoxazole, cefotaxime and nalidixic acid by Kirby Bauer disc diffusion method following CLSI (2011) guidelines. Subcultured colonies were taken from nutrient agar plates and turbid suspension was made as per $0.5 \mathrm{McF}$ arland standards by emulsifying colonial growth in LuriaBertani broth (LB) (HiMedia, India). A sterile cotton swab was dipped into LB and the swab was streaked on the entire surface of Mueller Hinton agar (HiMedia, India) three times, rotating the plate approximately 60 degrees after each application to ensure an even distribution of the inoculums. Finally, swab was done all around the edge of the agar surface. Using sterile tweezers, antibiotic discs were placed aseptically on the surface of Mueller Hinton agar plates. The plates were then incubated at $37^{\circ} \mathrm{C}$ for 24 hours.

Data analysis: The information was collected from questionnaire and finally tabulated. The data were analyzed by SPSS version 16 . The $\mathrm{p}$ value less than equal to 0.05 was considered statistically significant.

\section{RESULTS}

Prevalence of E. coli

Out of 400 samples, $15 \%$ were positive for E. coli.

Table 1: Prevalence of $E$. coli in urine samples from UTI suspected patients

\begin{tabular}{|c|c|c|c|}
\hline E. coli in urine samples & & Prevalence & \\
\hline Positive & & $60(15 \%)$ & \\
\hline Negative & & $340(85 \%)$ & \\
\hline \multicolumn{4}{|c|}{ Gender wise prevalence of $E$. coli } \\
\hline Gender & Number of subjects & UTI by $E$ coli & $\mathrm{p}$-value \\
\hline Male & 9 & $1(11.11 \%)$ & \multirow{2}{*}{$<0.05$} \\
\hline Female & 391 & $59(15.08 \%))$ & \\
\hline
\end{tabular}

Antibiotic susceptibility pattern of $E$. coli isolates

The most effective drugs for $E$. coli were found to be

Chloramphenicol (100\%), Cephoxitin (78.33\%) and
Ofloxacin (78.33\%). E. coli were resistant to Ampicillin $(100 \%)$, Amoxicillin (100\%) and Nalidixic acid (65\%).

Table 2: Antibiotic susceptibility pattern of E. coli isolates

\begin{tabular}{lccc}
\hline \multicolumn{1}{c}{ Antibiotics } & Resistant (\%) & Sensitive (\%) & p-value \\
\hline Amoxicillin & $60(100)$ & - & - \\
Ampicillin & $60(100)$ & - & - \\
Cefotaxime & $16(26.66)$ & $44(73.33)$ & $<0.001$ \\
Ceftriaxone & $15(25)$ & $45(75)$ & $<0.001$ \\
Cephoxitin & $13(21.66)$ & $47(78.33)$ & $<0.001$ \\
Chloramphenicol & - & $60(100)$ & - \\
Ciprofloxacin & $12(20)$ & $48(60)$ & $<0.001$ \\
Co-Trimoxazole & $23(38.33)$ & $37(61.66)$ & 0.018 \\
Gentamycin & $14(23.33)$ & $46(76.66)$ & $<0.001$ \\
Nalidixic acid & $39(65)$ & $21(35)$ & 0.01 \\
Norfloxacin & $31(51.66)$ & $29(48.33)$ & 0.584 \\
Ofloxacin & $13(21.66)$ & $47(78.33)$ & $<0.001$ \\
Tetracycline & $26(43.33)$ & $34(56.66)$ & 0.201 \\
Trimethoprim & $22(36.66)$ & $38(63.33)$ & 0.060 \\
\hline
\end{tabular}

\section{Multidrug resistant (MDR) E. coli}

Uropathogenic E. coli which showed resistance to three or more than three antibiotics were considered as multidrug resistant. $42(70 \%)$ isolates of E. coli were MDR out of 60 isolates. 
Table 3: Multidrug resistant (MDR) E. coli

\begin{tabular}{lc}
\hline Samples & Uropathogenic E. coli \\
\hline Total samples & 60 \\
Multidrug resistant & $42(70 \%)$
\end{tabular}

Antibiogram of biofilm producer and non-producer E. coli

Ampicillin and Amoxicillin were resisted by all isolates of E. coli. The biofilm producing E. coli showed high resistance to all antibiotics as compared to biofilm nonproducer E. coli

Table 4: Antibiogram of biofilm producer and non-producer E. coli

\begin{tabular}{lccc}
\hline Antibiotics & $\begin{array}{c}\text { \% of Biofilm Producing Resistant } \\
\text { to antibiotics }\end{array}$ & $\begin{array}{c}\text { \% of non-biofilm Producing } \\
\text { Resistant to antibiotics }\end{array}$ & P-value \\
\hline Amoxicillin & 100 & 100 & - \\
Ampicillin & 100 & 100 & - \\
Cefotaxime & 31.11 & 13.33 & 0.004 \\
Ceftriaxone & 31.11 & 6.66 & 0.001 \\
Cephoxitin & 24.44 & 13.33 & 0.019 \\
Chloramphenicol & - & - & - \\
Ciprofloxacin & 24.44 & 6.66 & 0.006 \\
Cotrimoxazole & 42.22 & 26.66 & 0.002 \\
Gentamycin & 28.88 & 6.66 & 0.002 \\
Nalidixic acid & 71.11 & 46.66 & $<0.001$ \\
Norfloxacin & 53.33 & 46.66 & 0.002 \\
Ofloxacin & 24.44 & 13.33 & 0.019 \\
Tetracycline & 44.44 & 40 & 0.007 \\
Trimethoprim & 42.22 & 20 & 0.001 \\
\hline
\end{tabular}

\section{DISCUSSION}

The overall prevalence of E. coli in urine samplesfrom UTI suspected patients was15\% (60/400). Neupane et al. (2016) and Khatri et al. (2017) showed very similar report of $15.5 \%$ and $14.1 \%$ respectively. In this study the prevalence of UTI by E. coli was higher in female population than in male population which was statistically significant $(p<0.05)$ which is consistent with many other studies.

In this study out of total 400 samples, 71 (17.77\%) urine samples showed significant growth of uropathogens $\left(\geq 10^{5} \mathrm{cfu} / \mathrm{mL}\right.$ ) in which $E$ coli was isolated from 60 (15\%) urine samples Ponnusamy et al. (2012) and Sherchan et al. (2016) reported comparatively higher percentage of E. coli $23.49 \%$ and $87.9 \%$ of UTI casesrespectively. According to a research done by Neupane et al. (2016), $18.8 \%$ of the sample population showed significant growth of bacteria which is very similar to our result. All E. coli isolates were sensitive to Chloramphenicol and resistant to Amoxicillin and Ampicillin. A very close similarity was revealed by Sharma et al. (2013) and Ouno et al. (2013).
In our study, 70\% E. coli were MDR. Baral et al. (2012) recorded $41.1 \%$ of MDR E. coli isolates in his investigation which was very less in comparison to our work. As per the experimentation done by Dehbanipour et al. (2016) and Poursina et al. (2018) multidrug resistant E. coli were $73 \%$ and $68 \%$ respectively and it was very close to our analysis. Multidrug resistance has become a major problem in the treatment of diseases. The resistance of UTI causing bacteria towards commonly used antibiotics is escalating both in developing and developed countries (Elsayed et al. 2017).

Among 60 E. coli isolates, $31.66 \%$ were strong biofilm producers, $21.66 \%$ moderately positive, $21.66 \%$ were weak ones and $25 \%$ were biofilm non-producers by using microtitre plate method which were in accordance with the findings of Neupane et al. (2016) and Khatri et al. (2017).

Biofilm producing microorganisms shows resistance to large number of antibiotics increasing antibiotic resistance up to 1000 folds and hence, higher concentration of antimicrobial is required to treat such microorganisms (Stewart et al. 2001). Inadequate 
amount of antibiotics reaching some areas of biofilm and inactiveness of bacteria located at the base of biofilm may be the reason for such resistance (Soto et al. 2014). In this investigation, both the biofilm producing and non-producing E. coli were resistant to Amoxicillin and Ampicillin (100\%). However, resistance to other antibiotics such as Nalidixic acid, Norfloxacin and Cotrimoxazole was comparatively higher among biofilm producers than biofilm non-producers. Furthermore, this study there was a statistical significance $(p<0.05)$ between biofilm formation and multidrug resistance (MDR) which was also reported by Murugan et al. (2011) and Kulkarni et al. (2018).

\section{CONCLUSION}

High prevalence of Multidrug resistant E. coli in UTI suspected patients alarms the need of prescribing antibiotics based only on culture and sensitivity reports. There is relation between the ability of biofilm formation and antibioticresistance in the bacterium resulting to the failure of antibacterial drugs.

\section{CONFLICT OF INTEREST}

The authors declare no conflict of interest.

\section{REFERENCES}

Anderson GG, Palermo JJ, Schilling JD, Roth R, Heuser J and Hultgren SJ (2003). Intracellular bacterial biofilm-like pods in urinary tract infections. Science 301(5629): 105-107.

Baral P, Neupane S, Marasini BP, Ghimire KR, Lekhak B and Shrestha B (2012). High prevalence of multidrug resistance in bacterial uropathogens from Kathmandu, Nepal. BMC Research Notes 5: 38.

Bhatta CP, Shrestha B, Khadka S, Swar S, Shah B and Pun K (2012). Etiology of urinary tract infection and drug resistance cases of uropathogenes. Journal of Kathmandu Medical College 1(2): 114-120.

Borucki MK, Peppin JD, White D, Loge F and Call DR (2003). Variation in biofilm formation among strains of Listeria monocytogenes. Environ Microbial 69: 7336-7342.

CLSI (2011). Performance standards for antimicrobial susceptibility testing. M100-S21. Clinical and Laboratory Standards Institute, Wayne PA.

Dehbanipour R, Rastaghi S, Sedighi M, Maleki N and Faghri J (2016). High Prevalence of multidrug- resistance uropathogenic E. coli strains, Isfahan, Iran. Journal of Natural Science 7(1): 22-26.

Elsayed TI, Ismail HAF, Elgamal SA and Gad AHA (2017). The occurrence of multidrug resistant $E$. coli which produce ESBL and cause urinary tract infections. Journal of Applied Microbiology and Biochemistry 1: 6-8.

Isenberg HD (2004). Clinical Microbiology Procedures Handbook ( $2^{\text {nd }}$ edition). ASM press Washington, D.C.

Karki A, Tiwari BR and Pradhan SB (2004). Study of bacteria isolated from urinary tract infection and their sensitivity pattren. Journal of the Nepal Medical Association 154(43): 200-203.

Karlowsky JA, Kelly LJ, Thornsberry C, Jones ME and Sahm DF (2002). Trends in antimicrobial resistance among urinary tract infection isolates of $E$. coli from female outpatients in the United States. Antimicrob Agents Chemother 46: 25402545.

Kass EH (1962). Pyelonephritis and bacteriuria A major problem in preventive medicine. Ann Intern Med 56: 46-53.

Kass EH (1957). Bacteriuria and the diagnosis of infections of the urinary tract: with observations on the use of methionine as a urinary antiseptic. AMA Archives of Internal Medicine 100(5): 709-714.

Khatri S, Pant ND, Neupane S, Bhandari S and Banjara MR (2017). Biofilm production in relation to extended spectrum beta-lactamase production and antibiotic resistance among uropathogenic E. coli. Janaki Medical College Journal of Medical Sciences 5(1): 61-63.

Komaroff AL (1986). Diagnostic decision: Urinalysis and urine culture in women with dysuria. Annals of Internal Medicine 104(2): 212-218.

Kostakioti M, Handjifrangiskou M and Hultgren SJ (2013). Bacterial biofilms: development, dispersal and therapeutic strategies in the dawn of the post-antibiotic era. Cold Spring Harb Perspect Med 3(4): a010306.

Kulkarni SR and Peerapur BV (2018). Analysis of antibiotic sensitivity profile of biofilm-forming uropathogenic E. coli. Journal of Natural Science, Biology and Medicine 9(2): 175-179. 
Kunin CM, Hua TH, Krishnan C, Van Arsdale WL and Hacker J (1993). Isolation of a nicotinamide requiring clone of E. coli 018: K1: H7 from women with acute cystitis: resemblance to strains found in neonatal meningitis. Clin Infect Dis 16(3): 412416.

Magiorakos AP, Srinivasan A, Carey RB, Carmeli Y, Falages ME, Giske CG, Harbarth S, Hindler JF, Kahlmeter G, Liljequist BO, Paterson DL, Rice LB, Stelling J, Struelens MJ, Vatopoulos A, Weber JT and Monnet DL (2011). Multidrug-resistant, extensively drug-resistant and pandrug-resistant bacteria: an international expert proposal for interim standard definitions for acquired resistance. Clinical Microbiology and Infection 18(3): 268-281.

Mashwal FA, Safi SHEI, George SJ, Adam AA and Jebakumar AZ (2017). Incidence and molecular characterization of the extended spectrum betalactamase-producing E. coli isolated from urinary tract infections in Eastern Saudi Arabia. Saudi Medical Journal 38(8): 811-815.

Murugan S, Devi PU and John PN (2011). Antimicrobial susceptibilty pattern of biofilm producing $E$. coli urinary tract infections. Current Research in Bacteriology 4(2): 73-80

Neupane S, Pant ND, Khatiwada S, Chaudhary R and Banjara MR (2016). Correlation between biofilm formation and resistance towards different commonly used antibiotics along with extended spectrum beta lactamase production in uropathogenic E. coli isolated from the patients suspected of urinary tract infection visiting Shree Birendra Hospital, Chhauni, Kathmandu, Nepal. Antimicrobial Resistance and Infection Control 5: 5.

Nicolle LE (2008). Uncomplicated urinary tract infection in adults including uncomplicated pyelonephritis. Urologic Clinics of North America 35: 1-12.

Ouno GA, Korir SC, Cheruiyota JC, Ratemo OD, Mabeya BM, Mauti GO, Mauti EM and Kiprono SJ (2013). Isolation, identification and characterization of urinary tract infectious bacteria and the effect of different antibiotics. Journal of Natural Sciences Research 3(6): 2224-3186.

Ponnusamy P, Natarajan V and Sevanan M (2012).
Invitro biofilm formation by uropathogenic $E$. coli and their antimicrobial susceptibility pattern. Asian Pacific Journal of Tropical Medicine 210-213.

Poursina F, Sepehrpour S and Mobasherizadeh S (2018). Biofilm formation in Non-multidrug-resistant E. coli isolated from patients with urinary tract infection in Isfahan, Iran. Advanced Biomedical Research 7: 40.

Pramodhini S, Niveditha S, Umadevi S, Kumar S and Stephen S (2012). Antibiotic resistance pattern of biofilm-forming uropathogens isolated from catheterized patients in Pondicherry, India. Australasian Medical Journal 5(7): 344-348.

Sharma AR, Bhatta DR, Shrestha J and Banjara MR (2013). Antimicrobial susceptibility of Escherichia coli isolated from urinary tract infected patients attending Bir hospital. Nepal Journal of Science and Technology, 14(1): 177-184.

Sherchan JB, Gurung P, Karkee P, Shrestha N and Ohara $H$ (2016). Microbiological and clinical profile of uropathogenic E. coli isolates in Kathmandu University Hospital. J Nepal Health Res Counc 14(32):33-38.

Soto SM (2014). Importance of biofilms in urinary tract infections: new therapeutic approaches. Advances in Biology Article ID 543974, 13 pages.

Stepanovic S, Vukovic D, Hola V, Bonqventura GD, Djukic S, Clrkovic I and Ruzicka F (2007). Quantification of biofilm in microtitre plates: Overview of testing conditions and practical recommendation for assessment of biofilm production by Staphylococci. Journal Compilation APMIS 115: 891-899.

Stewart PS and Costerton JW (2001). Antibiotic resistance of bacteria in biofilms. The Lancet 358(9276): 135-138.

Tenaillon O, Rodriquez VA, Gaut RL, McDonald P, Bennett AF, Long AD and Gaut BS (2012). The Molecular diversity of adaptive convergence. US National Library of Medicine National Institutes of Health 335(6067): 457-61.

Watnick P and Kolter R (2000). Biofilm, city of microbes. Journal of Bacteriology 182(10): 2675-2679. 